\title{
A NOVEL TWO - FACTOR HIGH ORDER FUZZY TIME SERIES WITH APPLICATIONS TO TEMPERATURE AND FUTURES EXCHANGE FORECASTING
}

\author{
S. M. Yusuf ${ }^{1}$, A. Mohammad ${ }^{2}$ and A. A. Hamisu ${ }^{3, *}$

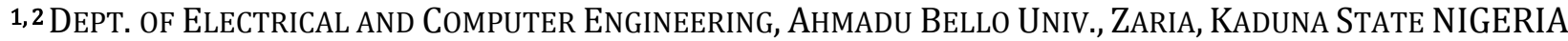 \\ 3DEPARTMENT OF CHEMICAL ENGINEERING, AHMADU BELlo UNIVERSITY, ZARIA, KADUNA NIGERIA \\ E-mail addresses.13heikullahi@gmail.com, 2masani@abu.edu.ng,3alamin446@gmail.com
}

\begin{abstract}
High order fuzzy time series forecasting methods are more suitable than first order fuzzy time series forecasting methods in dealing with linguistic values. However, existing high order methods lack persuasiveness in dealing objectively with multiple - factor fuzzy time series, recurrent number of fuzzy relationships, and assigning weights to elements of fuzzy forecasting rules. In this paper, a novel two - factor high - order fuzzy time series forecasting method based on fuzzy C-means clustering and particle swarm optimization is proposed to resolve these drawbacks. Fuzzy C-means clustering is utilized in the fuzzification phase to objectively partition the universe of discourse and enable processing of multiple factors. Then, particle swarm optimization is utilized to assign optimal weights to elements of fuzzy forecasting rules. Daily average temperatures of Taipei and Taiwan Futures Exchange (TAIFEX) are used as benchmark data. Average forecasting error performance of $0.85 \%$ was obtained for Taipei Temperature forecast. Mean squared error performance of 199.57 was obtained for Taiwan Futures Exchange forecast. The forecasting results showed that the proposed method has higher forecasting performance than other existing methods.
\end{abstract}

Keywords: fuzzy time series, fuzzy c-mean clustering, particle swarm optimization, forecasting, fuzzy relationships

\section{INTRODUCTION}

Forecasting is one of the most important topics of research for the modern scientists and engineers. As a result, several innovative forecasting methods have been developed. Amongst various well-known forecasting techniques, fuzzy time series-based methods are successfully used than traditional forecasting methods. Fuzzy time series forecasting is the application of linguistic mathematical reasoning to model and predict the future from a time series of linguistic historical observations. This method of forecasting, compared with traditional time series forecasting, takes care of uncertainties in observations over time, does not require restrictive assumptions and too much background knowledge of the observations [1]. Also, fuzzy time series forecasting methods are able to work with very small set of observations [2].

The use of fuzzy time series in forecasting was first introduced in 1993 by Song and Chissom [3]. Fuzzy time series forecasting comprises three processes: fuzzification, determining fuzzy relationships and defuzzification.
Fuzzification is the process of converting crisp observations to linguistic values by identifying variations in the crisp data [1]. In fuzzification, determination of interval lengths is important in partitioning the universe of discourse. The studies of [3-5], determined equal interval lengths, subjectively, to partition an arbitrary defined universe of discourse. Huarng [6] pointed that determining length of interval, objectively, is critical for improving forecasting performance in fuzzy time series. Mean and distribution approach in determining the number of intervals was proposed [1]. In [7], a ratio based interval length was presented and the forecasting results showed that unequal length of intervals improved fuzzy time series forecasting performance. In [9], Cheng et al proposed a multivariate fuzzy time series forecasting method. This hybrid method adopted fuzzy C-means clustering to objectively partition the universe of discourse into unequal intervals, define memberships that best explains the unknown structure of the observations and, eliminate the need to define universe of discourse, in fuzzy time series forecasting. 
Models in [10 - 18] proposed optimal approaches in searching for appropriate unequal length of intervals using evolutional algorithms.

Determining fuzzy relationships is critical in fuzzy time series forecasting. These relationships are logical associations between the linguistic future observations and fuzzified historical observations. While in $[3,4,19]$, relational matrix operation is adopted in determining fuzzy relationships, Chen [5] proposed fuzzy logical relationship groups. Yu suggested in [8], the assignment of weights to resolve issue of recurrent fuzzy relationship and to reflect the difference in their importance. Singh in [20], used a difference parameter as a fuzzy relationship for forecasting. In [21], Teoh et al suggested fuzzy rough set theory to generate forecasting rules after fuzzy relationship is discovered. Eleruja et al [22] and Mohammed et al [1] adopted the concept of fuzzy set groups to establish fuzzy relationships and optimized the defuzzification process using particle swarm optimization. Uslu et al [2] introduced a novel fuzzy time series technique that utilized genetic algorithm in the fuzzification process and assigned weights to recurrent fuzzy relationships to improve forecasting performance.

Defuzzification is the final stage in fuzzy time series forecasting. This is the process of deriving future crisp forecasts from fuzzy forecasting rules. While the centroid method was adopted in [3], arithmetic mean of centroids was adopted in [4] and many other studies. Kuo et al in [10] proposed a new Master Voting scheme to derive forecasts. Mohammed et al [1] adopted weighted sum of centroids to obtain forecasts using particle swarm optimization.

In this study, fuzzy C-means clustering was used, in the fuzzification process, to determine valid and useful unequal length of intervals for the universe of discourse and enable processing of multiple variables. Then, fuzzy set group was introduced to eliminate recurrent fuzzy relationships. Finally, particle swarm optimization was proposed to assign weights to elements of forecasting rules and obtain defuzzified forecasts.

The rest of this paper is organized as follows: A brief discussion of fuzzy time series, fuzzy C-means clustering and particle swarm optimization are described in Section 2. In Section 3, the proposed forecasting model is discussed. Section 4 discusses the results obtained from the application of the proposed model to two sets of observations. Finally, Section 5 presents the conclusion.

\section{THEORETICAL BACKGROUND}

In this section, fuzzy time series, fuzzy C-means clustering and particle swarm optimization are briefly reviewed.

\subsection{Fuzzy time series}

Fuzzy time series forecasting model is a mathematical forecasting model that assumes information needed to generate forecasts is contained in time series of linguistic historical data [1]. Fuzzy time series was first adopted in forecasting by Song and Chissom [3], to deal with incomplete and vague series of data by applying fuzzy logic. Fuzzy time series differ from traditional time series in that observations are not numeric values but linguistic values [23]. Its ability to work with a very small set of observations makes fuzzy time series forecasting outstanding $[2,24]$.

Definition 1: Let $f_{i}(t)(i=1,2,3 \ldots)$ be defined on $Y(t)(t=\cdots 0,1,2 \ldots)$ the universe of discourse, which is a subset of real numbers. If $F(t)$ is a collection of, $f_{i}(t)(i=1,2,3 \ldots)$ then $F(t)$ is called a fuzzy time series on. $Y(t)(t=\cdots 0,1,2 \ldots)$

Definition 2: Let $F(t)$ be a fuzzy time series. If $F(t)$ is caused by $F(t-1), F(t-2), \ldots F(t-n)$, then this fuzzy relationship is represented by $F(t-n) \ldots F(t-$ $2), F(t-1) \rightarrow F(t)$. this is called the one - factor $\mathrm{n}^{\text {th }}-$ order fuzzy time series.

Definition 3: Let $F_{1}(t), F_{2}(t)$ and $F(t)$ be a fuzzy time series. If $F(t)$ is caused by $\left(F_{1}(t-1), F_{2}(t-\right.$ $1)),\left(F_{1}(t-2), F_{2}(t-2)\right)$ and $\left.F_{1}(t-n), F_{2}(t-n)\right)$ then the fuzzy logical relationship is represented by

$$
\begin{gathered}
\left.\left.F_{1}(t-n), F_{2}(t-n)\right), \ldots, F_{1}(t-2), F_{2}(t-2)\right), F_{1}(t \\
\left.-1), F_{2}(t-2)\right) \rightarrow F(t)
\end{gathered}
$$

This is called the two - factor $\mathrm{n}^{\text {th }}$ order fuzzy time series forecasting model.

Definition 4: Let $F(t-2) A_{i, t-2}, F(t-1) A_{i, t-1}$ and $F(t)=A_{i .} \quad$ If $\quad A_{i, t-2}, A_{i, t-1}, \rightarrow A_{j,} \quad$, then $\left\{A_{i, t-2}, A_{i, t-1},\right\}$ is called a one - factor fuzzy set group (FSG) where $A_{i, t-2}$, and $A_{i, t-1}$.are two consecutive current states.

Definition 5 Let $F_{1}(t-2)=A_{i, t-2}, F_{1}(t-1)=A_{i, t-1}$, $F_{2}(t-2)=B_{i, t-2}, F_{2}(t-2)=B_{i, t-2}, F_{2}(t-1)=$

$B_{i, t-1}$ and $F(t)=A_{j} . A_{i}$ being the main - factor and $B_{i}$ being the second - factor. If $\left(A_{i, t-2}, B_{i, t-2}\right),\left(A_{i, t-1}, B_{i, t-1}\right) \rightarrow A_{j} \quad$ then $\left\{\left(A_{i, t-2}, B_{i, t-2}\right),\left(A_{i, t-1}, B_{i, t-1}\right) \rightarrow A_{j}\right\}$ is called a two factor fuzzy set group (FSG).

A fuzzy set group (FSG) is originally a second order fuzzy relation [1]. But, recurrent fuzzy set groups (FSGs) are extended to the third order to generate unique set of fuzzy relations. If the extended fuzzy set 
groups reoccur, the extension process continues until there is no recurrence of fuzzy relations.

\subsection{Fuzzy c-means clustering}

Fuzzy C-means clustering was first proposed by Dunn [25] and later generalized by Bezdek [26]. It has been successful in partitioning and fuzzifying observations by minimizing the cluster error objective function, given in equation (1), with respect to fuzzy memberships, and cluster centers [1]:

$$
\begin{aligned}
J_{\beta}(X, U, V)=\sum_{i=1}^{c} & \sum_{i=1}^{n} \mu_{i t}^{\beta} d^{2}\left(x_{t} ; V_{i}\right) \\
= & \sum_{i=1}^{c} \sum_{i=1}^{n} \mu_{i t}^{\beta} \times\left\|x_{t}-V_{i}\right\|
\end{aligned}
$$

$d^{2}\left(x_{t} ; V_{i}\right)$ is the Euclidean distance measure and $n$ is the number of observations, $x_{t} . \beta>1$ is the weighting exponent used to tune out noise in the observation set and $c \geq 2$ is the number of partitions in the observation set.

An iterative minimization algorithm is used to minimize $\mathrm{J}_{\beta}$ under the following constraints [9]:

$$
\begin{array}{ll}
0 \leq \mu_{i t} \leq 1 & \forall i, t \\
0<\sum_{t=1}^{n} u_{i t} \leq n, & \forall i \\
\sum_{t=1}^{c} u_{i t}=1, & \forall i
\end{array}
$$

In each iteration, the component of $V_{i}$ and $\mu_{\mathrm{it}}$ are updated using the following equations [19]:

$$
\begin{aligned}
v_{i} & =\frac{\sum_{t=1}^{n} \mu_{i t}{ }^{\beta} x_{t}}{\sum_{t=1}^{n} \mu_{i t}{ }^{\beta}} \\
\mu_{i t} & =\frac{1}{\sum_{i=1}^{c}\left(\frac{d\left(x_{t} ; V_{i}\right)}{d\left(x_{t} ; V_{k}\right)}\right)^{\frac{2}{\beta-1}}}
\end{aligned}
$$

The main fuzzy C-means clustering parameters to be set are; number of clusters, weighting exponents, maximum iteration, and precision. The maximum iteration and precision are known as stopping criteria [1]. In [9], an algorithm for fuzzy time series forecasting based on fuzzy C-means clustering was proposed for fuzzification. In this approach, fuzzification basically comprises three processes. Firstly, the algorithm utilizes fuzzy C-means clustering to identify unknown unequal partitions, and calculates memberships with respect to the measured partitions (cluster centers). Secondly, cluster centers are ranked in ascending order to define clusters as ordered linguistic variables. Finally, observations are fuzzified.

\subsection{Particle Swarm Optimization}

This is a stochastic optimization technique that is robust and fast in optimizing continuous non-linear functions. It was first introduced in 1995 by Kennedy and Eberhart [27]. Particle swarm optimization is a population - based evolutional algorithm that mimics the behavior of birds flocking or fish grouping in search for the location of food [22].

In particle swarm optimization algorithm, each solution is like a bird in the search space called 'particle' [21]. During particle swarm optimization implementation, a set of randomly generated particles, $n$, which are candidate solutions, are used to randomly initialize the process [1]. Then, an iterative search process is set in motion to improve the set of current solutions. The moving particle adjusts its velocity during any iteration according to:

$$
\begin{aligned}
V_{i, t+1}=W \times V_{i, t} & +C_{1} \times \operatorname{Rand}_{1} \times\left(X_{P}-X_{i, t}\right)+C_{2} \\
& \times \operatorname{Rand}_{2}\left(X_{g}-X_{i, t}\right)
\end{aligned}
$$

$V_{i, t}$ is the velocity of particle $i$ at $t^{\text {th }}$ iteration and $w$ is the inertial weight factor. Inertia weight factor is used to balance between local and global exploitations of the swarms. While, $X_{P} X_{g}$ and $X_{i, t}$ are particle's personal best, global best and current position, respectively, $C_{1}$ and $C_{2}$ are cognition and social learning factors, respectively. Rand $_{1}$ and Rand $_{2}$ are two randomly generated numbers set within the range of $[0,1]$.

Also, current particle position is adjusted by adding the new velocity to the current position as represented in:

$$
X_{i, t+1}=X_{i}+V_{i, t+1}
$$

The performance of each particle is measured according to the objective function, $\mathrm{J}_{\beta}$ to be solved. A fitness value is associated to each particle to be optimized, and the movement of each particle is directed by a randomly generated velocity parameter [1].

Swarm size, maximum iteration, learning factors, particles initial positions, inertial weight factor, and target fitness value are main parameters that must be set in the algorithm to allow particle swarm optimization produce optimal solutions.

\section{PROPOSED METHOD}

Recently, due to the need for improving forecasting performance, researchers have developed various fuzzy time series models. However, there is the need to further improve the fuzzification and defuzzification phases; especially to handle forecasting problems based on two - factor high order fuzzy time series. To improve on the fuzzification phase, fuzzy C-maens (FCM) clustering can be used to partition a two- factor 
fuzzy time series. To improve on the defuzzification phase, fuzzy set groups (FSGs) can be used to obtain a unique two - factor high order set of fuzzy relations. These fuzzy relations can easily be converted to IF THEN rules [1]. Finally, particle swarm optimization (PSO) can be adopted to assign optimal weights to elements in each forecasting rule. In this study, a new two - factor high order fuzzy time series method that uses fuzzy C-means (FCM) clustering in the fuzzification phase, takes into consideration recurrent fuzzy relations and, optimize the defuzzification phase using particle swarm optimization (PSO) has been proposed to improve forecasting performance.

The main advantages of the proposed method are as follows:

- The objective determination of unequal interval lengths is achieved by utilizing fuzzy C-means clustering algorithm.

- Also, the processing of two factor forecasting is enabled using fuzzy C-means clustering. This reduces mismatch between forecasts and actual historical observations.

- Recurrent two - factor fuzzy relationships are dealt with using fuzzy set groups (FSGs) to provide unique forecasts.

- The proposed method can have higher forecasting accuracy than other existing methods.

\subsection{Algorithm}

Step 1: Define the number of intervals and the parameters fuzzy C-means clustering algorithm.

After the number of intervals, $\mathrm{c}$, is determined, the parameters such as the number of cluster centers, fuzzy index, precision and maximum number of iteration are decided for the fuzzy C-means clustering algorithm. The number of cluster is set to the same value as the number of intervals required for each factor.

Step 2: Compute interval lengths and membership degrees for the main - factor and second - factor using the fuzzy C-means clustering algorithm.

Firstly, fuzzy C-means clustering is applied to compute the cluster centers for the main - factor. Then, same algorithm is applied to compute the cluster centers and membership degrees for the second - factor. The computed cluster centers are the set of unequal partitions for the historical observations.

Step 3: Obtain fuzzy sets for each factor by ordering clusters in ascending order.

Partitions produced by fuzzy C-means clustering algorithm are not orderly arranged like in the case of traditional fuzzy time series partitions [1]. Since fuzzy sets are only defined on ordered partitions, there is the need to order cluster centers. In this work, the main factor cluster centers are arranged in ascending order to define the main - factor fuzzy sets, $A,(r=1,2,3 \ldots \mathrm{c})$. While the second - factor cluster centers are arranged in ascending order to define the second - factor fuzzy sets, $B,(r=1,2,3 \ldots \mathrm{c})$.

Step 4: Fuzzify historical data: Here, numeric historical observations are converted to their linguistic values using the defined fuzzy sets and membership degrees of each observation computed. A linguistic variable, among defined fuzzy sets, is the linguistic value of an observation if in that fuzzy set, the observation has its highest degree [1].

Step 5: Establish unique two - factor FSGs: For instance, when we observe the second order relation such as:

$F(t-2)=A_{i, t-2}, \quad F(t-1)=A_{i, t-1}$ and $F(t)=A_{j}$ for any time $t$, this fuzzy relation is represented by $A_{i, t-2}, A_{i, t-1} \rightarrow A_{j}$. A two - factor fuzzy relationship is expressed in FSG by collecting the current states in braces as $\left\{\left(A_{i, t-2}, B_{i, t-2}\right),\left(A_{i, t-1}, B_{i, t-1}\right)\right\}$

Also, when an FSG appears more than once, the order of repeated FSGs is continuously incremented by one until every FSG is unique.

Step 6: Extract IF - THEN rules from FSGs. These rules are generated on the basis of the content of main factor in the fuzzy set groups. The rule is of the form:

$$
\begin{aligned}
\operatorname{if}(F(t-1)= & A_{i, t-1} \Lambda F(t-2) \\
& =A_{r, t-2} \Lambda \ldots \Lambda F(t-n+1) A_{r, t-n+1} \\
& \left.=\Lambda F(t-n)=A_{r, t-n}\right) \text { Then } w_{t-1} \\
& =? \Lambda w_{t-2}=? \Lambda \ldots \Lambda w_{t-n+1}=? \Lambda w_{t-n} \\
& =?
\end{aligned}
$$

Here, $w_{t-n}$ is the weight of the previous main - factor at time $(t-n), t$ is the time (period) of the future main factor whose forecast is required, $n=\mathrm{t}$ is the time (period) of the previous main - factor data point matched in a forecasting rule.

The weight $w_{t-n}$ represents the strength of fuzzy logical relationship between the previous historical data at $n$ and future forecast at $t$ [1].

Step 7: Train IF - THEN rules using PSO algorithm.

Optimal weights are generated for the content of fuzzy set groups (FSGs), by training the IF-THEN rules using particle swarm optimization. Each weight represents the strength of relationship between a past value and a future forecast. Generating optimal weights for forecasting rules will reduce mismatch between the forecasts and actual historical observations [1]. When particle swarm optimization algorithm is applied on an IF-THEN rule, a fitness value for each particle is obtained using equation (10). 


$$
J=(Y(t)-A(t))^{2}
$$

Here, $Y(t)$ is the future forecast and $A(t)$ is the actual observation.

The future forecast $Y(t)$ is obtained as follows:

$$
Y(t)=\sum_{i=1}^{n} a_{t-i} \times X_{i}
$$

Here, $a_{t-i}$ is the defuzzified value of a linguistic main factor observation in the forecasting rule. $X_{i}$ is the corresponding weight assigned to the linguistic main factor observation in the forecasting rule.

Step 8: Derive forecasts.

By utilizing optimal weights obtained in Step 7, equation (11) is used to compute forecasts.

\section{APPLICATION}

In order to verify the performance of the proposed two - factor high order forecasting method, this was applied to two different time series observations: Daily average temperatures of Taipei and Taiwan Futures Exchange (TAIFEX) [29]. The obtained results are compared with the results obtained from other fuzzy time series techniques in the literature using Mean Squared Error (MSE) and Average Forecasting Error Rate (AFER) criteria as shown in (12)and (13), respectively.

$$
\begin{aligned}
M S E & =\frac{\sum_{i=1}^{n}(Y(t)-A(t))^{2}}{N} \\
A F E R & =\frac{1}{n} \sum_{i=1}^{n} \frac{|Y(t)-A(t)|}{A(t)} \times 100
\end{aligned}
$$

For each time series observations, the decided FCM clustering parameters are as follows [1]:

- Maximum number of iterations as 100 .

- $\quad$ Precision $\varepsilon=0.00001$.

- $\beta=2$

- $\quad c$ is experimented as from 7 to 20 .

A suitable value of $c$ is selected by evaluating the MSE value between historical observations and their defuzzified values. After experimentation, the $c$ value with the smallest MSE value was taken as the best solution among these solutions.

Also, for each time series observation, the PSO parameters are defined as follows [1]:

- $\quad$ Swarm size, $n=5$.

- $\quad$ Maximum number of iterations, $K_{\max }=500$.

- Target fitness value as minimum squared error of 1.

- Minimum and maximum particles' position is limited to $[0,1]$.

- Minimum and maximum velocity should be in the range $[-0.01,0.01]$.

- Learning factors $C_{1}$ and $C_{2}$ is both equal to 2 .

- Inertial coefficient, $w$ as 1.4 .

FCM clustering and PSO are executed in C\#.

\subsection{Forecasting daily average temperatures of Taipei}

The proposed model is first implemented on the time series observations of average temperature (main factor) and cloud density (Second - factor) in Taipei for the month of June, 1996. The best result was obtained in the case where $c=7$ and 12 for average temperature and cloud density, respectively.

Table 1 shows the cluster centers and their corresponding defined fuzzy sets; obtained by ranking in ascending order. Table 2 presents the generated two - factor fuzzy set groups and optimal weights assigned to the content of the forecasting rules for the temperature observation set. The forecasted average daily temperature for Taipei is presented in Table 3. Figure 1 shows the plot of the forecasts and real historical observations against time.

As seen in Figure 1, there is a good matching between the actual and forecasted temperature observations. Although, there were a number of outliers but, the spread at the spot in which outliers occurred was quite narrow (for example, June 23rd and 25th). So, these outliers had no significant impact on model reliability.

Table 1: Cluster Centers and Defined Fuzzy Sets for Daily Taipei Temperatures and Cloud Densities in June

\begin{tabular}{|c|c|c|c|c|c|c|c|c|}
\hline \multicolumn{3}{|c|}{ Temperature (Main Factor) } & \multicolumn{5}{c|}{ Cloud Densty (Second Factor) } \\
\hline Cluster & Center & Fuzzy Set & Cluster & Center & Fuzzy Set & Cluster & Center & Fuzzy Set \\
\hline 4 & 26.12 & $\mathrm{~A}_{1}$ & 2 & 10.08 & $\mathrm{~B}_{1}$ & 6 & 42.24 & $\mathrm{~B}_{7}$ \\
\hline 3 & 27.24 & $\mathrm{~A}_{2}$ & 5 & 13.08 & $\mathrm{~B}_{2}$ & 4 & 45.38 & $\mathrm{~B}_{8}$ \\
\hline 6 & 28.14 & $\mathrm{~A}_{3}$ & 1 & 19.31 & $\mathrm{~B}_{3}$ & 7 & 55.33 & $\mathrm{~B}_{9}$ \\
\hline 1 & 28.94 & $\mathrm{~A}_{4}$ & 3 & 23.74 & $\mathrm{~B}_{4}$ & 11 & 60 & $\mathrm{~B}_{10}$ \\
\hline 7 & 29.01 & $\mathrm{~A}_{5}$ & 8 & 29.3 & $\mathrm{~B}_{5}$ & 10 & 63 & $\mathrm{~B}_{11}$ \\
\hline 5 & 29.62 & $\mathrm{~A}_{6}$ & $\mathrm{~A}_{7}$ & & 35.54 & $\mathrm{~B}_{6}$ & 12 & 96 \\
\hline 2 & 30.35 & & & & & & \\
\hline
\end{tabular}




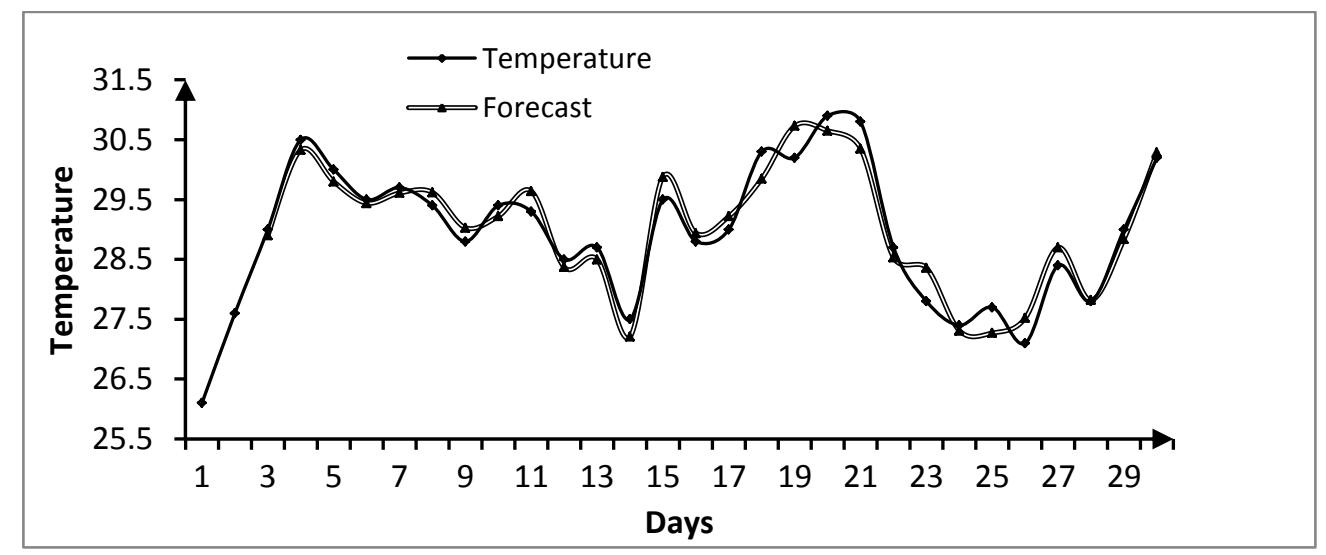

Figure 1: Actual and Forecasted Temperature vs. Time

Table 2: Generated Fuzzy Set Groups and Optimal Weights for Temperature

\begin{tabular}{|c|c|c|c|c|c|c|}
\hline Day & Temperature & Linguistic & Cloud Density & Linguistic & FSG & Optimal Weights \\
\hline 1 & 26.1 & $\mathrm{~A}_{1}$ & 36 & $\mathrm{~B}_{6}$ & & \\
\hline 2 & 27.6 & $\mathrm{~A}_{2}$ & 23 & $\mathrm{~B}_{4}$ & & \\
\hline 3 & 29 & $\mathrm{~A}_{5}$ & 23 & $\mathrm{~B}_{4}$ & $\left\{\left(\mathrm{~A}_{1}, \mathrm{~B}_{6}\right),\left(\mathrm{A}_{2}, \mathrm{~B}_{4}\right)\right\}$ & $\{0.46,0.62\}$ \\
\hline 4 & 30.5 & $\mathrm{~A}_{7}$ & 10 & $\mathrm{~B}_{1}$ & $\left\{\left(\mathrm{~A}_{2}, \mathrm{~B}_{4}\right),\left(\mathrm{A}_{5}, \mathrm{~B}_{4}\right)\right\}$ & $\{0.40,0.67\}$ \\
\hline 5 & 30 & $\mathrm{~A}_{7}$ & 13 & $\mathrm{~B}_{2}$ & $\left\{\left(\mathrm{~A}_{5}, \mathrm{~B}_{4}\right),\left(\mathrm{A}_{7}, \mathrm{~B}_{1}\right)\right\}$ & $\{0.41,0.59\}$ \\
\hline 6 & 29.5 & $\mathrm{~A}_{6}$ & 30 & $\mathrm{~B}_{5}$ & $\left\{\left(\mathrm{~A}_{7}, \mathrm{~B}_{1}\right),\left(\mathrm{A}_{7}, \mathrm{~B}_{2}\right)\right\}$ & $\{0.38,0.59\}$ \\
\hline 7 & 29.7 & $\mathrm{~A}_{6}$ & 45 & $\mathrm{~B}_{8}$ & $\left\{\left(\mathrm{~A}_{7}, \mathrm{~B}_{2}\right),\left(\mathrm{A}_{6}, \mathrm{~B}_{5}\right)\right\}$ & $\{0.39,0.60\}$ \\
\hline 8 & 29.4 & $\mathrm{~A}_{6}$ & 35 & $\mathrm{~B}_{6}$ & $\left\{\left(\mathrm{~A}_{6}, \mathrm{~B}_{5}\right),\left(\mathrm{A}_{6}, \mathrm{~B}_{8}\right)\right\}$ & $\{0.40,0.60\}$ \\
\hline 9 & 28.8 & $\mathrm{~A}_{4}$ & 26 & $\mathrm{~B}_{4}$ & $\left\{\left(\mathrm{~A}_{6}, \mathrm{~B}_{8}\right),\left(\mathrm{A}_{6}, \mathrm{~B}_{6}\right)\right\}$ & $\{0.38,0.60\}$ \\
\hline 10 & 29.4 & $\mathrm{~A}_{6}$ & 21 & $\mathrm{~B}_{3}$ & $\left\{\left(\mathrm{~A}_{6}, \mathrm{~B}_{6}\right),\left(\mathrm{A}_{4}, \mathrm{~B}_{4}\right)\right\}$ & $\{0.41,0.59\}$ \\
\hline 11 & 29.3 & $\mathrm{~A}_{5}$ & 43 & $\mathrm{~B}_{7}$ & $\left\{\left(\mathrm{~A}_{4}, \mathrm{~B}_{4}\right),\left(\mathrm{A}_{6}, \mathrm{~B}_{3}\right)\right\}$ & $\{0.40,0.61\}$ \\
\hline 12 & 28.5 & $\mathrm{~A}_{3}$ & 40 & $\mathrm{~B}_{7}$ & $\left\{\left(\mathrm{~A}_{6}, \mathrm{~B}_{3}\right),\left(\mathrm{A}_{5}, \mathrm{~B}_{7}\right)\right\}$ & $\{0.38,0.59\}$ \\
\hline 13 & 28.7 & $\mathrm{~A}_{4}$ & 30 & $\mathrm{~B}_{5}$ & $\left\{\left(\mathrm{~A}_{5}, \mathrm{~B}_{7}\right),\left(\mathrm{A}_{3}, \mathrm{~B}_{7}\right)\right\}$ & $\{0.41,0.59\}$ \\
\hline 14 & 27.5 & $\mathrm{~A}_{2}$ & 29 & $\mathrm{~B}_{5}$ & $\left\{\left(\mathrm{~A}_{3}, \mathrm{~B}_{7}\right),\left(\mathrm{A}_{4}, \mathrm{~B}_{7}\right)\right\}$ & $\{0.35,0.60\}$ \\
\hline 15 & 29.5 & $\mathrm{~A}_{6}$ & 30 & $\mathrm{~B}_{5}$ & $\left\{\left(\mathrm{~A}_{4}, \mathrm{~B}_{7}\right),\left(\mathrm{A}_{2}, \mathrm{~B}_{5}\right)\right\}$ & $\{0.43,0.64\}$ \\
\hline 16 & 28.8 & $\mathrm{~A}_{4}$ & 46 & $\mathrm{~B}_{8}$ & $\left\{\left(\mathrm{~A}_{2}, \mathrm{~B}_{5}\right),\left(\mathrm{A}_{6}, \mathrm{~B}_{5}\right)\right\}$ & $\{0.41,0.60\}$ \\
\hline 17 & 29 & $\mathrm{~A}_{5}$ & 55 & $\mathrm{~B}_{9}$ & $\left\{\left(\mathrm{~A}_{6}, \mathrm{~B}_{5}\right),\left(\mathrm{A}_{4}, \mathrm{~B}_{8}\right)\right\}$ & $\{0.41,0.59\}$ \\
\hline 18 & 30.3 & $\mathrm{~A}_{7}$ & 19 & $\mathrm{~B}_{3}$ & $\left\{\left(\mathrm{~A}_{4}, \mathrm{~B}_{8}\right),\left(\mathrm{A}_{5}, \mathrm{~B}_{9}\right)\right\}$ & $\{0.43,0.60\}$ \\
\hline 19 & 30.2 & $\mathrm{~A}_{7}$ & 15 & $\mathrm{~B}_{2}$ & $\left\{\left(\mathrm{~A}_{5}, \mathrm{~B}_{9}\right),\left(\mathrm{A}_{7}, \mathrm{~B}_{3}\right)\right\}$ & $\{0.40,0.63\}$ \\
\hline 20 & 30.9 & $\mathrm{~A}_{7}$ & 56 & $\mathrm{~B}_{9}$ & $\left\{\left(\mathrm{~A}_{7}, \mathrm{~B}_{3}\right),\left(\mathrm{A}_{7}, \mathrm{~B}_{2}\right)\right\}$ & $\{0.41,0.60\}$ \\
\hline 21 & 30.8 & $\mathrm{~A}_{7}$ & 60 & $\mathrm{~B}_{10}$ & $\left\{\left(\mathrm{~A}_{7}, \mathrm{~B}_{2}\right),\left(\mathrm{A}_{7}, \mathrm{~B}_{9}\right)\right\}$ & $\{0.40,0.60\}$ \\
\hline 22 & 28.7 & $\mathrm{~A}_{4}$ & 96 & $\mathrm{~B}_{12}$ & $\left\{\left(\mathrm{~A}_{7}, \mathrm{~B}_{9}\right),\left(\mathrm{A}_{7}, \mathrm{~B}_{10}\right)\right\}$ & $\{0.36,0.58\}$ \\
\hline 23 & 27.8 & $\mathrm{~A}_{3}$ & 63 & $\mathrm{~B}_{11}$ & $\left\{\left(\mathrm{~A}_{7}, \mathrm{~B}_{10}\right),\left(\mathrm{A}_{4}, \mathrm{~B}_{12}\right)\right\}$ & $\{0.38,0.60\}$ \\
\hline 24 & 27.4 & $\mathrm{~A}_{2}$ & 28 & $\mathrm{~B}_{5}$ & $\left\{\left(\mathrm{~A}_{4}, \mathrm{~B}_{12}\right),\left(\mathrm{A}_{3}, \mathrm{~B}_{11}\right)\right\}$ & $\{0.37,0.59\}$ \\
\hline 25 & 27.7 & $\mathrm{~A}_{3}$ & 14 & $\mathrm{~B}_{2}$ & $\left\{\left(\mathrm{~A}_{3}, \mathrm{~B}_{11}\right),\left(\mathrm{A}_{2}, \mathrm{~B}_{5}\right)\right\}$ & $\{0.34,0.65\}$ \\
\hline 26 & 27.1 & $\mathrm{~A}_{2}$ & 25 & $\mathrm{~B}_{4}$ & $\left\{\left(\mathrm{~A}_{2}, \mathrm{~B}_{5}\right),\left(\mathrm{A}_{3}, \mathrm{~B}_{2}\right)\right\}$ & $\{0.38,0.61\}$ \\
\hline 27 & 28.4 & $\mathrm{~A}_{3}$ & 29 & $\mathrm{~B}_{5}$ & $\left\{\left(\mathrm{~A}_{3}, \mathrm{~B}_{2}\right),\left(\mathrm{A}_{2}, \mathrm{~B}_{4}\right)\right\}$ & $\{0.41,0.63\}$ \\
\hline 28 & 27.8 & $\mathrm{~A}_{1}$ & 55 & $\mathrm{~B}_{9}$ & $\left\{\left(\mathrm{~A}_{2}, \mathrm{~B}_{4}\right),\left(\mathrm{A}_{3}, \mathrm{~B}_{5}\right)\right\}$ & $\{0.36,0.64\}$ \\
\hline 29 & 29 & $\mathrm{~A}_{6}$ & 29 & $\mathrm{~B}_{5}$ & $\left\{\left(\mathrm{~A}_{3}, \mathrm{~B}_{5}\right),\left(\mathrm{A}_{1}, \mathrm{~B}_{9}\right)\right\}$ & $\{0.44,0.63\}$ \\
\hline 30 & 30.2 & $\mathrm{~A}_{7}$ & 19 & $\mathrm{~B}_{3}$ & $\left\{\left(\mathrm{~A}_{1}, \mathrm{~B}_{6}\right),\left(\mathrm{A}_{2}, \mathrm{~B}_{4}\right)\right\}$ & $\{0.44,0.69\}$ \\
\hline
\end{tabular}


Table 3: Forecasted Daily Average Temperature for Taipei

\begin{tabular}{|c|c|c|c|c|c|c|c|}
\hline Day & $\begin{array}{c}\text { Actual Temperature, } \\
\mathrm{A}_{i}\end{array}$ & $\begin{array}{c}\text { Forecast, } \\
\mathrm{F}_{i}\end{array}$ & FER & Day & $\begin{array}{c}\text { Actual Temperature, } \\
\mathrm{A}_{i}\end{array}$ & $\begin{array}{c}\text { Forecast, } \\
\mathrm{F}_{i}\end{array}$ & FER \\
\hline 1 & 26.1 & & & 16 & 28.8 & 28.94 & 0.00486 \\
\hline 2 & 27.6 & & & 17 & 29 & 29.22 & 0.00759 \\
\hline 3 & 29 & 28.9 & 0.00345 & 18 & 30.3 & 29.85 & 0.01485 \\
\hline 4 & 30.5 & 30.33 & 0.00557 & 19 & 30.2 & 30.73 & 0.01755 \\
\hline 5 & 30 & 29.8 & 0.00667 & 20 & 30.9 & 30.65 & 0.00809 \\
\hline 6 & 29.5 & 29.44 & 0.00203 & 21 & 30.8 & 30.35 & 0.01461 \\
\hline 7 & 29.7 & 29.61 & 0.00303 & 22 & 28.7 & 28.53 & 0.00592 \\
\hline 8 & 29.4 & 29.62 & 0.00748 & 23 & 27.8 & 28.36 & 0.02014 \\
\hline 9 & 28.8 & 29.03 & 0.00799 & 24 & 27.4 & 27.31 & 0.00328 \\
\hline 10 & 29.4 & 29.22 & 0.00612 & 25 & 27.7 & 27.27 & 0.01552 \\
\hline 11 & 29.3 & 29.64 & 0.116 & 26 & 27.1 & 27.52 & 0.0155 \\
\hline 12 & 28.5 & 28.37 & 0.00456 & 27 & 28.4 & 28.7 & 0.01056 \\
\hline 13 & 28.7 & 28.5 & 0.00697 & 28 & 27.8 & 27.82 & 0.00072 \\
\hline 14 & 27.5 & 27.21 & 0.01055 & 29 & 29 & 28.84 & 0.00552 \\
\hline \multirow[t]{2}{*}{15} & 29.5 & 29.88 & 0.01288 & 30 & 30.2 & 30.29 & 0.00298 \\
\hline & & & & & AFER & & 0.00845 \\
\hline
\end{tabular}

A comparative presentation of the temperature's AFER for the proposed method and some other methods is given in Table 4. As seen in Table 4, it is obvious that the proposed technique produces a superior forecasting performance.

\subsection{Forecasting Taiwan Futures Exchange (TAIFEX):}

The proposed technique is also implemented on the time series observations of Taiwan Futures Exchange (TAIFEX) and TAIEX between August 3 and November 30,1998 . TAIFEX is the main - factor while TAIEX is the second - factor. The best result was obtained in the case where $c=16$ and 13 for TAIFEX and TAIEX, respectively. Table 5 presents the cluster centers and their corresponding linguistic values obtained by ranking in ascending order.

The generated two - factor fuzzy set groups and optimal weights assigned to the content of the forecasting rules, for the observation set is shown in
Table 6. The forecasted average daily temperature for TAIFEX is presented in Table 7. Additionally, a comparative presentation of TAIFEX for the proposed method and some other methods, using MSE, is given in Table 8. As seen in Table 8, the proposed method produces a superior result with respect to the forecasting performance.

Figure 2 shows the plot the forecasts and real observations against time. The graph also shows a good match between the forecasts and actual TAIFEX observations.

Table 4: A Comparative Presentation of Temperatures' Forecasts

\begin{tabular}{cccc}
\hline$[14]$ & {$[30]$} & {$[31]$} & $\begin{array}{c}\text { Proposed } \\
\text { Method }\end{array}$ \\
\hline $1.44 \%$ & $2.88 \%$ & $1.23 \%$ & $0.85 \%$ \\
\hline
\end{tabular}

Table 5: Cluster Centers and Defined Fuzzy Sets for Daily TAIFEX Temperatures and TAIEX in August 3 - November 30,1998

\begin{tabular}{ccccccccccccc}
\hline \multicolumn{1}{c}{ TAIFEX (Main Factor) } & \multicolumn{1}{c}{ TAIEX (Second Factor) } \\
\hline Cluster & Center & $\begin{array}{c}\text { Fuzzy } \\
\text { Set }\end{array}$ & Cluster & Center & $\begin{array}{c}\text { Fuzzy } \\
\text { Set }\end{array}$ & Cluster & Center & $\begin{array}{c}\text { Fuzzy } \\
\text { Set }\end{array}$ & Cluster & Center & $\begin{array}{c}\text { Fuzzy } \\
\text { Set }\end{array}$ \\
\hline 11 & 6200.01 & $\mathrm{~A}_{1}$ & 10 & 7038.44 & $\mathrm{~A}_{9}$ & 12 & 6290.3 & $\mathrm{~B}_{1}$ & 4 & 7025.8 & $\mathrm{~B}_{7}$ \\
9 & 6406.09 & $\mathrm{~A}_{2}$ & 16 & 7221.36 & $\mathrm{~A}_{10}$ & 5 & 6485.6 & $\mathrm{~B}_{2}$ & 1 & 7178.1 & $\mathrm{~B}_{8}$ & \\
3 & 6430.02 & $\mathrm{~A}_{3}$ & 2 & 7286.58 & $\mathrm{~A}_{11}$ & 13 & 6737.5 & $\mathrm{~B}_{3}$ & 6 & 7277.9 & $\mathrm{~B}_{9}$ \\
15 & 6566.15 & $\mathrm{~A}_{4}$ & 7 & 7324.12 & $\mathrm{~A}_{12}$ & 8 & 6818.5 & $\mathrm{~B}_{4}$ & 11 & 7365.2 & $\mathrm{~B}_{10}$ \\
13 & 6713.42 & $\mathrm{~A}_{5}$ & 4 & 7362.44 & $\mathrm{~A}_{13}$ & 7 & 6893.3 & $\mathrm{~B}_{5}$ & 9 & 7479.3 & $\mathrm{~B}_{11}$ \\
6 & 6780.66 & $\mathrm{~A}_{6}$ & 5 & 7469.73 & $\mathrm{~A}_{14}$ & 2 & 6963.8 & $\mathrm{~B}_{6}$ & 3 & 7526.3 & $\mathrm{~B}_{12}$ \\
14 & 6854.45 & $\mathrm{~A}_{7}$ & 8 & 7512.82 & $\mathrm{~A}_{15}$ & & & & 10 & 7579.9 & $\mathrm{~B}_{13}$ \\
1 & 6941.67 & $\mathrm{~A}_{8}$ & 12 & 7555.95 & $\mathrm{~A}_{16}$ & & & & & & & \\
\hline
\end{tabular}


Table 6: Generated Fuzzy Set Groups and Optimal Weights for Temperature

\begin{tabular}{|c|c|c|c|c|c|c|}
\hline Date & TAIFEX & Linguistic & TAIEX & Linguistic & FSG & Optimal Weights \\
\hline 3 & 7552 & $A_{16}$ & 7599 & $\mathrm{~B}_{13}$ & & \\
\hline 4 & 7560 & $A_{16}$ & 7593 & $\mathrm{~B}_{13}$ & & \\
\hline 5 & 7487 & $A_{14}$ & 7500 & $B_{11}$ & $\left\{\left(A_{16}, B_{13}\right),\left(A_{16}, B_{13}\right)\right\}$ & $\{0.374,0.619\}$ \\
\hline 6 & 7462 & $A_{14}$ & 7472 & $B_{11}$ & $\left\{\left(\mathrm{~A}_{16}, \mathrm{~B}_{13}\right),\left(\mathrm{A}_{14}, \mathrm{~B}_{11}\right)\right\}$ & $\{0.372,0.624\}$ \\
\hline 7 & 7515 & $A_{15}$ & 7530 & $\mathrm{~B}_{12}$ & $\left\{\left(\mathrm{~A}_{14}, \mathrm{~B}_{11}\right),\left(\mathrm{A}_{14}, \mathrm{~B}_{11}\right)\right\}$ & $\{0.378,0.628\}$ \\
\hline 10 & 7365 & $A_{13}$ & 7372 & $B_{10}$ & $\left\{\left(A_{14}, B_{11}\right),\left(A_{15}, B_{12}\right)\right\}$ & $\{0.363,0.620\}$ \\
\hline 11 & 7360 & $A_{13}$ & 7384 & $B_{10}$ & $\left\{\left(A_{15}, B_{12}\right),\left(A_{13}, B_{10}\right)\right\}$ & $\{0.369,0.623\}$ \\
\hline 12 & 7330 & $A_{12}$ & 7352 & $B_{10}$ & $\left\{\left(A_{13}, B_{10}\right),\left(A_{13}, B_{10}\right)\right\}$ & $\{0.370,0.625\}$ \\
\hline 13 & 7291 & $A_{11}$ & 7363 & $\mathrm{~B}_{10}$ & $\left\{\left(A_{13}, B_{10}\right),\left(A_{12}, B_{10}\right)\right\}$ & $\{0.372,0.621\}$ \\
\hline 14 & 7320 & $A_{12}$ & 7348 & $\mathrm{~B}_{10}$ & $\left\{\left(A_{13}, B_{10}\right),\left(A_{12}, B_{10}\right),\left(A_{11}, B_{10}\right)\right\}$ & $\{0.115,0.318,0.568\}$ \\
\hline 15 & 7300 & $A_{11}$ & 7372 & $\mathrm{~B}_{10}$ & $\left\{\left(A_{11}, B_{10}\right),\left(A_{12}, B_{10}\right)\right\}$ & $\{0.374,0.624\}$ \\
\hline 17 & 7219 & $A_{10}$ & 7274 & $\mathrm{~B}_{9}$ & $\left\{\left(A_{11}, B_{10}\right),\left(A_{12}, B_{10}\right),\left(A_{11}, B_{10}\right)\right\}$ & $\{0.114,0.313,0.562\}$ \\
\hline 18 & 7220 & $A_{10}$ & 7182 & $\mathrm{~B}_{8}$ & $\left\{\left(A_{11}, B_{10}\right),\left(A_{10}, B_{9}\right)\right\}$ & $\{0.372,0.624\}$ \\
\hline 19 & 7285 & $A_{11}$ & 7293 & $\mathrm{~B}_{9}$ & $\left\{\left(A_{10}, B_{9}\right),\left(A_{10}, B_{8}\right)\right\}$ & $\{0.378,0.630\}$ \\
\hline 20 & 7274 & $A_{11}$ & 7271 & $\mathrm{~B}_{9}$ & $\left\{\left(A_{10}, B_{8}\right),\left(A_{11}, B_{9}\right)\right\}$ & $\{0.380,0.622\}$ \\
\hline 21 & 7225 & $A_{10}$ & 7213 & $\mathrm{~B}_{8}$ & $\left\{\left(A_{11}, B_{9}\right),\left(A_{11}, B_{9}\right)\right\}$ & $\{0.362,0.629\}$ \\
\hline 24 & 6955 & $A_{8}$ & 6958 & $\mathrm{~B}_{6}$ & $\left\{\left(A_{11}, B_{9}\right),\left(A_{10}, B_{8}\right)\right\}$ & $\{0.356,0.602\}$ \\
\hline 25 & 6949 & $A_{8}$ & 6908 & $\mathrm{~B}_{5}$ & $\left\{\left(\mathrm{~A}_{10}, \mathrm{~B}_{8}\right),\left(\mathrm{A}_{8}, \mathrm{~B}_{6}\right)\right\}$ & $\{0.369,0.617\}$ \\
\hline 26 & 6790 & $A_{6}$ & 6814 & $\mathrm{~B}_{14}$ & $\left\{\left(\mathrm{~A}_{8}, \mathrm{~B}_{6}\right),\left(\mathrm{A}_{8}, \mathrm{~B}_{5}\right)\right\}$ & $\{0.359,0.620\}$ \\
\hline 27 & 6835 & $\mathrm{~A}_{7}$ & 6813 & $\mathrm{~B}_{4}$ & $\left\{\left(\mathrm{~A}_{8}, \mathrm{~B}_{5}\right),\left(\mathrm{A}_{6}, \mathrm{~B}_{14}\right)\right\}$ & $\{0.377,0.622\}$ \\
\hline 28 & 6695 & $\mathrm{~A}_{5}$ & 6724 & $\mathrm{~B}_{3}$ & $\left\{\left(A_{6}, B_{14}\right),\left(A_{7}, B_{4}\right)\right\}$ & $\{0.362,0.619\}$ \\
\hline 29 & 6728 & $\mathrm{~A}_{5}$ & 6736 & $\mathrm{~B}_{3}$ & $\left\{\left(A_{7}, B_{4}\right),\left(A_{5}, B_{3}\right)\right\}$ & $\{0.370,0.642\}$ \\
\hline 31 & 6566 & $\mathrm{~A}_{4}$ & 6550 & $\mathrm{~B}_{2}$ & $\left\{\left(A_{5}, B_{3}\right),\left(A_{5}, B_{3}\right)\right\}$ & $\{0.363,0.614\}$ \\
\hline 1 & 6409 & $\mathrm{~A}_{2}$ & 6335 & $B_{1}$ & $\left\{\left(A_{5}, B_{3}\right),\left(A_{4}, B_{2}\right)\right\}$ & $\{0.361,0.607\}$ \\
\hline 2 & 6430 & $\mathrm{~A}_{3}$ & 6472 & $\mathrm{~B}_{2}$ & $\left\{\left(A_{4}, B_{2}\right),\left(A_{2}, B_{1}\right)\right\}$ & $\{0.376,0.618\}$ \\
\hline 3 & 6200 & $A_{1}$ & 6251 & $\mathrm{~B}_{1}$ & $\left\{\left(A_{2}, B_{1}\right),\left(A_{3}, B_{2}\right)\right\}$ & $\{0.356,0.609\}$ \\
\hline 4 & 6403.2 & $\mathrm{~A}_{2}$ & 6463 & $\mathrm{~B}_{2}$ & $\left\{\left(A_{3}, B_{2}\right),\left(A_{1}, B_{1}\right)\right\}$ & $\{0.382,0.636\}$ \\
\hline 5 & 6697.5 & $A_{5}$ & 6756 & $\mathrm{~B}_{3}$ & $\left\{\left(A_{1}, B_{1}\right),\left(A_{2}, B_{2}\right)\right\}$ & $\{0.406,0.652\}$ \\
\hline 7 & 6722.3 & $\mathrm{~A}_{5}$ & 6801 & $\mathrm{~B}_{4}$ & $\left\{\left(A_{2}, B_{2}\right),\left(A_{5}, B_{3}\right)\right\}$ & $\{0.381,0.638\}$ \\
\hline 8 & 6859.4 & $A_{7}$ & 6942 & $\mathrm{~B}_{6}$ & $\left\{\left(A_{5}, B_{3}\right),\left(A_{5}, B_{4}\right)\right\}$ & $\{0.365,0.613\}$ \\
\hline 9 & 6769.6 & $A_{6}$ & 6895 & $\mathrm{~B}_{5}$ & $\left\{\left(A_{5}, B_{4}\right),\left(A_{7}, B_{6}\right)\right\}$ & $\{0.370,0.625\}$ \\
\hline 10 & 6709.75 & $\mathrm{~A}_{5}$ & 6804 & $\mathrm{~B}_{4}$ & $\left\{\left(A_{7}, B_{6}\right),\left(A_{6}, B_{5}\right)\right\}$ & $\{0.367,0.619\}$ \\
\hline 11 & 6726.5 & $\mathrm{~A}_{5}$ & 6842 & $\mathrm{~B}_{4}$ & $\left\{\left(A_{6}, B_{5}\right),\left(A_{5}, B_{4}\right)\right\}$ & $\{0.370,0.628\}$ \\
\hline 14 & 6774.55 & $A_{6}$ & 6860 & $\mathrm{~B}_{5}$ & $\left\{\left(A_{5}, B_{4}\right),\left(A_{5}, B_{4}\right)\right\}$ & $\{0.361,0.617\}$ \\
\hline 15 & 6762 & $A_{6}$ & 6858 & $\mathrm{~B}_{5}$ & $\left\{\left(A_{5}, B_{4}\right),\left(A_{6}, B_{5}\right)\right\}$ & $\{0.375,0.626\}$ \\
\hline 16 & 6952.75 & $A_{8}$ & 6973 & $\mathrm{~B}_{6}$ & $\left\{\left(A_{6}, B_{5}\right),\left(A_{6}, B_{5}\right)\right\}$ & $\{0.385,0.640\}$ \\
\hline 17 & 6906 & $A_{8}$ & 7001 & $\mathrm{~B}_{7}$ & $\left\{\left(A_{6}, B_{5}\right),\left(A_{8}, B_{6}\right)\right\}$ & $\{0.376,0.628\}$ \\
\hline 18 & 6842 & $A_{7}$ & 6962 & $\mathrm{~B}_{6}$ & $\left\{\left(A_{8}, B_{6}\right),\left(A_{8}, B_{7}\right)\right\}$ & $\{0.361,0.615\}$ \\
\hline 19 & 7039 & $A_{9}$ & 7150 & $\mathrm{~B}_{8}$ & $\left\{\left(A_{8}, B_{6}\right),\left(A_{8}, B_{7}\right),\left(A_{7}, B_{6}\right)\right\}$ & $\{0.126,0.323,0.573\}$ \\
\hline 21 & 6861 & $A_{7}$ & 7029 & $\mathrm{~B}_{7}$ & $\left\{\left(A_{7}, B_{6}\right),\left(A_{9}, B_{8}\right)\right\}$ & $\{0.364,0.620\}$ \\
\hline 22 & 6926 & $A_{8}$ & 7034 & $\mathrm{~B}_{7}$ & $\left\{\left(A_{9}, B_{8}\right),\left(A_{7}, B_{7}\right)\right\}$ & $\{0.377,0.623\}$ \\
\hline 23 & 6852 & $\mathrm{~A}_{7}$ & 6962 & $\mathrm{~B}_{6}$ & $\left\{\left(A_{7}, B_{7}\right),\left(A_{8}, B_{7}\right)\right\}$ & $\{0.371,0.621\}$ \\
\hline 24 & 6890 & $A_{7}$ & 6980 & $\mathrm{~B}_{6}$ & $\left\{\left(A_{7}, B_{7}\right),\left(A_{8}, B_{7}\right),\left(A_{7}, B_{6}\right)\right\}$ & $\{0.116,0.319,0.567\}$ \\
\hline 25 & 6871 & $A_{7}$ & 6980 & $\mathrm{~B}_{6}$ & $\left\{\left(A_{8}, B_{7}\right),\left(A_{7}, B_{6}\right),\left(A_{7}, B_{6}\right)\right\}$ & $\{0.116,0.316,0.570\}$ \\
\hline 28 & 6840 & $A_{7}$ & 6911 & $\mathrm{~B}_{5}$ & $\left\{\left(A_{7}, B_{6}\right),\left(A_{7}, B_{6}\right),\left(A_{7}, B_{6}\right)\right\}$ & $\{0.102,0.327,0.568\}$ \\
\hline 29 & 6806 & $A_{6}$ & 6885 & $\mathrm{~B}_{5}$ & $\left\{\left(A_{7}, B_{6}\right),\left(A_{7}, B_{5}\right)\right\}$ & $\{0.371,0.629\}$ \\
\hline 30 & 6787 & $A_{6}$ & 6834 & $\mathrm{~B}_{4}$ & $\left\{\left(A_{7}, B_{5}\right),\left(A_{6}, B_{5}\right)\right\}$ & $\{0.369,0.627\}$ \\
\hline
\end{tabular}




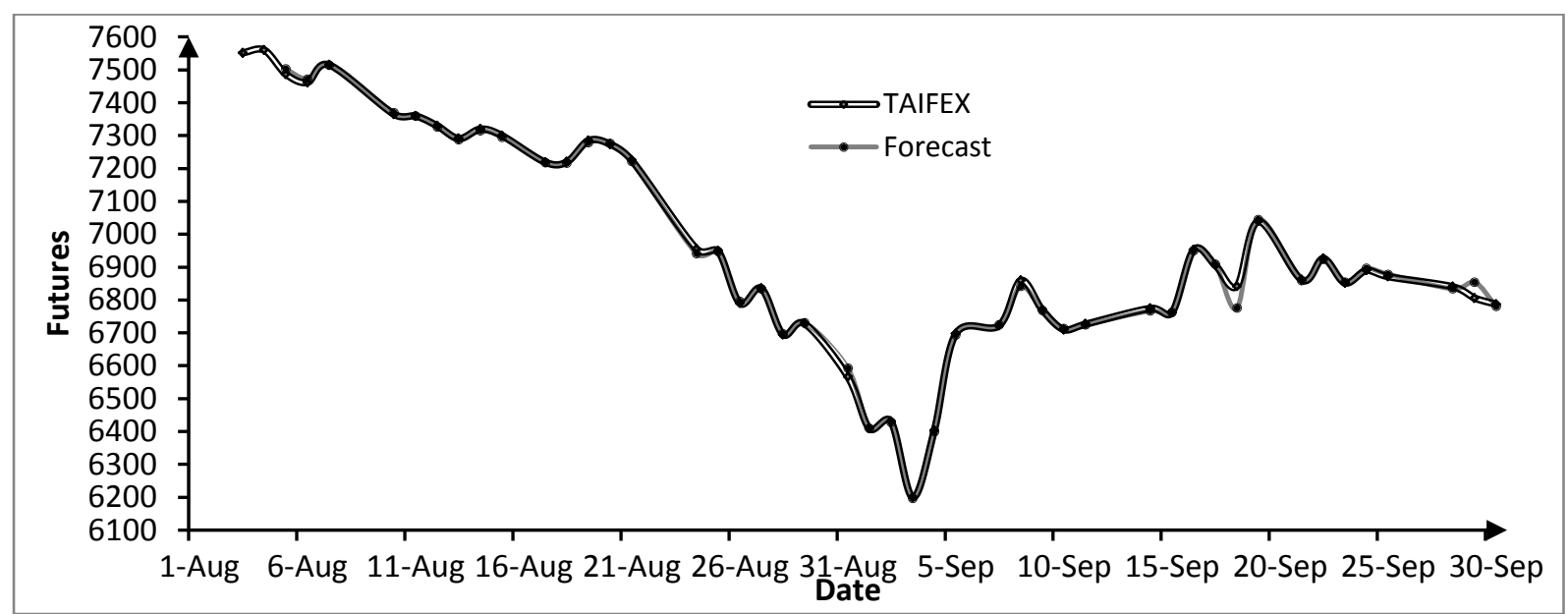

Figure 2: Graph of Forecasts of the Proposed Method and Actual Observations of TAIFEX

Table 7: Forecasted TAIFEX from August 3 - September 30, 1998.

\begin{tabular}{|c|c|c|c|c|c|}
\hline Date & Actual TAIFEX, $A_{i}$ & Forecast, $\mathrm{F}_{\mathrm{i}}$ & Date & Actual TAIFEX, $\mathrm{A}_{\mathrm{i}}$ & Forecast, $F_{i}$ \\
\hline 3-Aug & 7552 & & 2-Sep & 6430 & 6427.84 \\
\hline 4-Aug & 7560 & & 3-Sep & 6200 & 6196.45 \\
\hline 5-Aug & 7487 & 7503.06 & 4-Sep & 6403.2 & 6399.47 \\
\hline 6-Aug & 7462 & 7471.92 & 5-Sep & 6697.5 & 6693.97 \\
\hline 7-Aug & 7515 & 7514.55 & 7-Sep & 6722.3 & 6723.88 \\
\hline 10-Aug & 7365 & 7369.46 & 8-Sep & 6859.4 & 6840.97 \\
\hline 11-Aug & 7360 & 7359.03 & 9-Sep & 6769.6 & 6767.99 \\
\hline 12-Aug & 7330 & 7325.63 & 10-Sep & 6709.75 & 6712.81 \\
\hline 13-Aug & 7291 & 7287.11 & 11-Sep & 6726.5 & 6724.87 \\
\hline 14-Aug & 7320 & 7314.53 & 14-Sep & 6774.55 & 6767.13 \\
\hline 15-Aug & 7300 & 7295.43 & 15-Sep & 6762 & 6762.23 \\
\hline 17-Aug & 7219 & 7218.18 & 16-Sep & 6952.75 & 6950.18 \\
\hline 18-Aug & 7220 & 7216.74 & 17-Sep & 6906 & 6908.89 \\
\hline 19-Aug & 7285 & 7279.13 & 18-Sep & 6842 & 6775.07 \\
\hline 20-Aug & 7274 & 7276.37 & 19-Sep & 7039 & 7044.41 \\
\hline 21-Aug & 7225 & 7221 & 21-Sep & 6861 & 6858.85 \\
\hline 24-Aug & 6955 & 6941.28 & 22-Sep & 6926 & 6923.81 \\
\hline 25-Aug & 6949 & 6947.69 & 23-Sep & 6852 & 6853.78 \\
\hline 26-Aug & 6790 & 6795.89 & 24-Sep & 6890 & 6895.98 \\
\hline 27-Aug & 6835 & 6834.58 & 25-Sep & 6871 & 6878.28 \\
\hline 28-Aug & 6695 & 6697.5 & 28-Sep & 6840 & 6833.89 \\
\hline 29-Aug & 6728 & 6731.05 & 29-Sep & 6806 & 6854.45 \\
\hline 31-Aug & 6566 & 6592.58 & 30-Sep & 6787 & 6780.77 \\
\hline 1-Sep & 6409 & 6409.19 & & & \\
\hline
\end{tabular}

Table 8: A Comparative Presentation of TAIFEX Forecasts

\begin{tabular}{cccc}
\hline & {$[14]$} & {$[29]$} & Proposed Method \\
\hline MSE & 1364.56 & 287.32 & 199.57 \\
\hline
\end{tabular}

\section{CONCLUSION}

It has been observed that high order fuzzy time series lacks persuasiveness in dealing with multiple factors fuzzy time series observations, recurrent fuzzy relation and assigning weights to elements of a fuzzy rule affects forecasting performance of fuzzy time series. In this study, a novel two - factor high order fuzzy time series method which considers the number of recurrences in a second order fuzzy logic relationship table and assigns optimal weights to elements of a fuzzy rule has been proposed. Fuzzy C-means clustering is integrated in the fuzzification phase to partition observation sets objectively and enable processing of multiple factors while multiple - factor fuzzy set group is adopted in the defuzzification 
process to generate unique set of fuzzy relations. Also, particle swarm optimization is integrated in the defuzzification process to assign optimal weights to elements of a fuzzy forecasting rule. Experimental results on the temperature of Taipei and Taiwan futures exchange observations demonstrate that the proposed forecasting method provides more accurate forecasts.

In the future, there is the need for more applications of the proposed method to validate the general applicability. And, also integrating two - factor high order fuzzy set groups with different fuzzy time series forecasting methods can be studied.

\section{REFERENCES}

[1] Yusuf, S. M., Mu'azu, M. B., Akinsanmi, O. "A Novel Hybrid Fuzzy Time Series Approach with Applications to Enrollments and Car Road Accidents", International Journal of Computer Applications, 129(2), pp.37-44, 2015.

[2] Uslu, V. R, Bas, E., Yolcu, U. and Egrioglu, E."A fuzzy time series approach based on weights determined by the recurrences of fuzzy relations", Swarm and Evolutionary Computation, pp. 19-26, 2014.

[3] Song, Q. and Chissom, B. S. "Forecasting enrollments with fuzzy time series-Part I", Fuzzy Sets Syst., 54, pp. 1-9, 1993.

[4] Song, Q. and Chissom B. S. "Fuzzy time series and its models", Fuzzy Sets Syst., 54, pp. 269-277, 1993.

[5] Chen, S. M. "Forecasting enrollments based on fuzzy time-series", Fuzzy Sets Syst., 81, pp. 311319, 1996.

[6] Huarng, K. "Effective length of intervals to improve forecasting in fuzzy time- series", Fuzzy Sets Syst., 123, 2001, pp. 387-394.

[7] Huarng, K. and Yu, T. H. K. "Ratio-based lengths of intervals to improve fuzzy time series forecasting", IEEE Trans. Syst. ManCybern. Part B: Cybern., 36, pp. 328-340, 2006.

[8] Yu, H. K. "Weighted fuzzy time series models for TAIEX forecasting", Physica A, 349, 2005, pp. 609624.

[9] Cheng, C. H., Cheng, G. W. and Wang, J. W. "Multiattribute fuzzy time series method based on fuzzy clustering", Expert Syst. Appl., 34, pp. 1235-1242, 2008.

[10] Kuo, I. H., Horng, S. J., Kao, T. W, Lin, T. L., Lee, C. L. and Pan, Y. "An improved method of forecasting enrolments based on fuzzy time series and particle swarm optimization" Expert Syst. Appl., 36, pp. 6108-6117, 2009.

[11] Chen, S. M. and Chung, N. Y. "Forecasting enrolments using high order fuzzy time series and genetic algorithms",Int. J. Intell. Syst., 21, pp. 485501, 2006.

[12] Egrioglu, E., Aladag, C. H., Yolcu, U., Uslu, V. R. and Basaran, M. A. "Finding an optimal interval length in high order fuzzy time series", Expert Syst. Appl., 37, pp. 5052-5055, 2010.

[13] Egrioglu, E., Aladag, C. H., Basaran, M. A., Uslu, V. R. and Yolcu U. "A new approach based on the optimization of the length of intervals in fuzzy time series", J. Intell. Fuzzy Syst., 22, , pp.15-19 2011.

[14] Lee, L. W., Wang, L. H., Chen, S. M. and Leu Y. H. Handling forecasting problems based on two factor high-order fuzzy time series. IEEE Trans. Fuzzy Syst. 14 (3), pp. 468-477, 2006.

[15] Kuo, I. H., Horng, S. J., Chen, Y. H., Run, R. S., Kao, T. W., Chen, R. J., Lai, J. L. and Lin T. L. "Forecasting TAIFEX based on fuzzy time series and particle swarm optimization", Expert Syst. Appl., 37, pp. 1494-1502, 2010.

[16] Davari, S., Zarandi, M. H. F. and Turksen, I. B. "An Improved fuzzy time series forecasting model based on particle swarm intervalization" ,The 28th North American Fuzzy Information Processing Society Annual Conferences, NAFIPS, Cincinnati, Ohio, USA, 2009.

[17] Park, J. I., Lee, D. J., Song, C. K. and Chun M. G. "TAIFEX and KOSPI200 forecasting based on two factors high order fuzzy time series and particle swarm optimization", Expert Syst. Appl., 37, pp. 959-967, 2010.

[18] Hsu, L. Y., Horng, S. J., Kao, T. W., Chen, Y. H., Run, R. S., Chen, R. J, Lai, J. L. and Kuo, I. H."Temperature prediction and TAIFEX forecasting based on fuzzy relationships and MTPSO techniques", Expert Syst. Appl., 37, pp. 2756-2770, 2010.

[19] Aladag, C. H., Yolcu, U., Egrioglu, E. and Dalar, A. Z. A new time invariant fuzzy time series forecasting method based on particle swarm optimization. Appl. Soft Comput., 12, 2012, pp. 3291-3299, 2012.

[20] Singh, S. R. "A simple method of forecasting based on fuzzy time series" Applied Mathematics and Comput., 186, pp. 330-339, 2007.

[21] Teoh, H. J., Cheng, C. H., Chu, H. H. and Chen, J. S. "Fuzzy time series model based on probabilistic approach and rough set rule induction for empirical research in stock markets", Data and Knowledge Eng., 67, pp. 103-117, 2008. 
[22] Eleruja, S. A, Mu'azu, M. B. and Dajab, D. D. "Application of trapezoidal fuzzification approach (TFA) and particle swarm optimization (PSO) in fuzzy time series (FTS) forecasting", Proceedings of ICAI, 1, 2012, pp. 80-89, 2012.

[23] Li, S. T., Cheng, Y. C. and Lin, S. Y. "A FCM - based deterministic forecasting model for fuzzy time series" Computer and Mathematics with Applications, 56, pp. 3052 - 3063, 2008.

[24] Yolcu, U. "A new approach based on optimization of ratio for seasonal fuzzy time series", Iranian Journal of Fuzzy Syst., 13, 2016, pp. 19 - 36, 2016.

[25] Dunn, J. C. “A fuzzy relative of ISODATA process and its use in detecting compact well - separated clusters", Cybernetics, 3, 1974, pp. 32 - 57. 1974.

[26] Bezdek, J. C. "Pattern recognition with fuzzy objective function algorithms", New York. Plenum, 1981.

[27] Kennedy, J. and Eberhart, R. "Particle swarm optimization", Proceedings of IEEE International
Conference on Neural Network, 1942 - 1948, 1995.

[28] Mahnam, M. and Ghomi, S. M. T. F. "A particle swarm optimization algorithm for forecasting based on time variant fuzzy time series", IJIEPR, ISSN: 2008-4889, 23, 2012, pp.269-276, 2012.

[29] Chen, S. M. and Tanuwijaya, K. "Fuzzy forecasting based on high-order fuzzy logical relationships and automatic clustering techniques", Expert Systems with Applications, 38, 2011, pp. 15425 15437, 2011.

[30] Chen, S. M. and Hwang, J. R. "Temperature prediction using fuzzy time series" Cybernetics, $30(2)$, pp. $263-275,2000$.

[31] Chen, S. M. and Chang Y. C. "Multivariable forecasting based on fuzzy clustering and fuzzy rule interpolation techniques" Information Sciences, 180, pp. 4772 - 4783, 2010. 